\title{
O IMPACTO DO PENSAMENTO NEOLIBERAL SOBRE A "NOVA" REFORMA DO ENSINO MÉDIO- LEI No 13.415/2017: A EDUCAÇÃO PÚBLICA EM RISCO
}

\author{
Dayanna Pereira Santos \\ Edson Silva de Carvalho \\ Instituto Federal de Educação, Ciência e Tecnologia de Goiás (IFG), Goiânia, \\ Goiás, Brasil
}

\begin{abstract}
Resumo: Este artigo discute a questão da Reforma do Ensino Médio sob a influência do pensamento neoliberal na educação, colocando em evidência os seus dilemas e impasses. Objetiva-se, assim, analisar as relações entre o neoliberalismo e as políticas públicas na área de educação após promulgação da "nova1" reforma do ensino médio por meio da Lei no 13.415, sancionada em 16 de fevereiro de 2017. Considerando esse contexto, as reflexões apresentadas buscam problematizar a hierarquização e flexibilização curricular, a ênfase no ensino de competências e seu caráter mercadológico. Em contraposição, ressalta-se o papel social dos Institutos Federais de Educação em prol da defesa de um ensino médio que proporcione uma formação integrada, politécnica e que toma o trabalho como um princípio educativo.
\end{abstract}

Palavras-chave: Neoliberalismo; Reforma do Ensino Médio; Formação Integrada.

\section{NEOLIBERALISMO: ORIGEM E PRINCÍPIOS}

O neoliberalismo foi estabelecido como movimento a partir de 1947, sob a liderança de Friedrich Von Hayek, com um encontro de intelectuais conservadores na cidade de Mont Pelerin, na Suíça, onde se instituiu um grupo de ativistas contra as políticas do chamado Estado de Bem-Estar Social, fundamentadas no arcabouço teórico de John Maynard Keynes (FREITAS, 2018). A outra corrente do movimento teve como locus os Estados Unidos e vinculou-se à escola de Chicago gerida por Milton Friedman, defensor do monetarismo e da liberdade plena do mercado. Friedman, embasado nos pressupostos teóricos de Hayek, refutava as políticas de Estado do New Deal, de Franklin Delano Roosevelt, tomadas como intervencionistas e pró-sindicatos. A terceira corrente do neoliberalismo vinculou-se às teorias do filósofo Karl Popper, autor de A lógica da descoberta cientifica (1934) e Conjecturas e Refutações (1963). 
Na década de 1970, as sociedades capitalistas tiveram sua economia afetada por intensa recessão, com as grandes e médias corporações trabalhando abaixo da sua capacidade de produção. Com isso, houve baixas taxas de crescimento econômico e altos índices de inflação. Nesse contexto, foi estabelecido cenário fecundo para a implementação dos princípios das teses neoliberais, sobretudo com as eleições de Margaret Thatcher, em 1979, na Inglaterra, e Ronald Reagan, em 1980, nos Estados Unidos. As principais teses neoliberais operadas na prática, com pequenas diferenças entre os dois países, a depender da particularidade de cada um, são as seguintes: política de desestatização; expansão da iniciativa privada; viabilização das reformas fiscais como forma de incentivar os agentes econômicos; redução constante e progressiva dos gastos públicos nas áreas sociais; enfraquecimento dos movimentos sindicais. De acordo com Harvey (2008, p. 13), no neoliberalismo

[...] o papel do Estado é criar e preservar uma estrutura institucional apropriada a essas práticas; o Estado tem de garantir, por exemplo, a qualidade e a integridade do dinheiro. Deve também estabelecer as estruturas e funções militares, de defesa, da polícia e legais requeridas para garantir direitos de propriedade individuais e para assegurar, se necessário pela força, o funcionamento apropriado dos mercados.

Com o fragmento acima, é possível depreender que a política de mercado engendrada pelo neoliberalismo implica, especialmente, um conteúdo de caráter ideológico de empoderamento e alargamento, de alcance nacional e internacional, das grandes agências empresariais. Trata-se de uma tendência histórica real de incremento de empresas oligopolistas (e mesmo de monopólios) que vem se verificando desde o princípio da década de 1970 até os finais dos anos 1990², com avanço ainda mais agressivo na contemporaneidade. A lógica dominante é a do lucro máximo, intrínseco a qualquer unidade de produção capitalista, seja no mercado de produtos, serviços ou financeiro. Com efeito, investe-se nas funções policialescas e militares, cunhando-se as condições apropriadas para uma atuação mais rigorosa e eficiente na coerção às insatisfações que venham a se manifestar na sociedade civil.

De modo específico, considera-se que, na lógica neoliberal, as relações humanas são mercantilizadas, manipuladas, pois o sujeito pensa e opera para o capital, para a produção, sob a égide da ilusão de que é ele quem elabora e dá cumprimento ao processo, enquanto, na verdade, a deliberação do quê e de como produzir, realizar, atuar, não cabe ao trabalhador. Portanto, esse processo mercantiliza a potência de trabalho, a força humana, os elementos de produção, as relações sociais, e produz valor para si. Um exemplo disso é a intervenção do Banco Mundial nas políticas educacionais brasileiras com o objetivo de garantir os interesses do capital, restringindo o papel da educação à formação de mão de obra para o mercado de trabalho (FRIGOTTO; CIAVATTA, 2003).

De acordo com Gentili (1996), o neoliberalismo extrapola os limites como padrão de organização socioprodutiva, constituindo-se também num aparelho ideológico de alienação a serviço da classe dominante. Por ter uma finalidade em si mesmo, o processo produtivo, sob a lógica do capital, aliena o trabalhador, pois é somente para produzir que 
ele existe. Assim, a divisão social do trabalho e a divisão industrial do trabalho geram a alienação e extinguem as relações entre os homens, uma vez que esses não têm o comando do processo de produção e não se beneficiam do produto de seu trabalho.

Para Freitas (2018), em relação à educação, o neoliberalismo busca fazer com que seu pensamento predomine, isto é, que as suas teses direcionem as políticas educacionais, a fim de garantir: privatização das instituições escolares; implementação do modelo de gestão empresarial; adequação dos currículos escolares conforme os interesses do mercado. Para tanto, os neoliberais adotam discursos, tais como: a escola pública não é eficiente devido a sua ordem estatal; a gestão pública é incapaz; a influência do Estado faz a escola improdutiva etc. Sob esse prisma, qualidade da educação - adotada como bandeira por distintos setores governamentais e empresariais - contrai valor estratégico como condição para o refinamento do método de acumulação de riquezas e aprofundamento do capitalismo. Todavia, a qualidade é definida pelo máximo de produção com o mínimo de investimento, quanto menor os gastos, mais competitiva torna-se a instituição.

Com efeito, é possível depreender que a lógica neoliberal na educação promove uma prática pedagógica baseada na flexibilidade e nas competências solicitadas pelo sistema econômico. Para Frigotto e Ciavatta (2013), a ideologia neoliberal de acumulação impõe à educação um modo de produção e transmissão do conhecimento altamente instrumental, de base técnica e útil, promovendo o empobrecimento da formação humana. Nesse contexto, é supervalorizado o papel da formação profissional voltada às demandas do mercado, passando, de tal modo, por uma flexibilidade curricular que atenda a essas demandas. Essa base formativa está pautada por contravalores alinhados ao desenvolvimento do modo de reprodução do sistema capitalista, que, por meio da ideologia neoliberal, engendra o discurso de inversão da educação em mercadoria.

\section{A “NOVA" REFORMA DO ENSINO MÉDIO E OS VELHOS IDEAIS NEOLIBERAIS}

No contexto do pós-golpe jurídico-parlamentar de 2016, foi promulgada a Lei no 13.415/2017, responsável pela "nova" reforma do Ensino Médio em vigor, que objetiva a flexibilização da matriz curricular e assim possibilita ao estudante optar por certa área de conhecimento para aprimorar seus estudos. A atual matriz prevê uma parte comum e obrigatória a todas as escolas por meio da Base Nacional Comum Curricular (BNCC) e outra seção flexível. Tal mudança é justificada pelo objetivo de aproximar ainda mais a escola das novas demandas profissionais do mercado de trabalho. Nesse caso, a BNCC define as competências e conhecimentos oferecidos a todos os estudantes na parte comum em 1.800 horas, envolvendo linguagens e suas tecnologias; matemática e suas tecnologias; ciências da natureza e suas tecnologias; ciências humanas e sociais aplicadas e a formação técnica e profissional. Opera, pois, um modelo pedagógico que busca contemplar a ideia de que uma integração com a educação profissional, sob a prerrogativa da formação, ao mesmo tempo, do jovem para o mundo do trabalho e a prática social e para a continuidade de estudos, articule metas de interesse nacional com os interesses do público específico.

Nesse sentido, destaca-se que a preocupação com a formação da classe trabalhadora em fase escolar e com aspectos como a evasão e a defasagem de aprendizagem não é coeva e tem gerado distintas abordagens na busca da investigação 
de suas origens e no desenvolvimento de projetos necessários para a sua suplantação. Destarte, considera-se que a constituição de um projeto de educação realça as disputas de concepções e estratégias de cada período histórico. Segundo Motta e Frigotto (2017), a ideia de promover no ensino médio o desenvolvimento de habilidades e competências que maximizam a inserção do jovem no mercado de trabalho constitui-se em uma ideologia injusta e ardilosa, pois os "cortes no orçamento da educação e os repasses de recursos públicos para setores privados ofertarem cursos aligeirados e de baixo valor tecnológico agregado vão de encontro à ideologia do capital humano" (Ibid., p. 361). Isso implica pensar que a trajetória de implementação e uma política pautada pela imbricada relação entre a formação para o trabalho e o ensino médio não deveriam acontecer de modo impositivo, via medida provisória ou decretos, visto que pressupõe efetiva discussão e o enfrentamento com diferentes frações da sociedade, inclusive com os contrários.

Portanto, apenas propor a formação da classe trabalhadora em consonância com o discurso produtivista e suas demandas atuais, como a flexibilidade e adaptabilidade, não é suficiente para garantir a melhoria da qualidade da educação. Para o autor, a melhoria da qualidade da educação brasileira incide no aumento e não no congelamento dos investimentos nas instituições públicas, conforme posto na Emenda Constitucional n. $95 / 2016$, que prevê drástica limitação aos gastos públicos do governo federal por vinte anos.

Nesse contexto, anula-se o horizonte da formação omnilateral e mais uma vez entra em cena a ideia de educação como mercadoria, na qual existe a ligação dos objetivos das políticas educacionais às demandas econômicas e de livre mercado. Para Freitas (2018, p. 10), a contemporaneidade da educação brasileira conta com a forte retomada dos ideais neoliberais "a partir do Golpe jurídico-parlamentar de 2016 que afastou a coalizão do PT do poder, colocando em cena a retomada do liberalismo econômico". Para o autor, tal realidade influencia a educação brasileira na medida em que prevê a inclusão da escola no livre mercado por meio de um movimento global de reforma da educação.

Dentre os desdobramentos desse cenário, o "novo" ensino médio brasileiro, empreendido pelo governo de Michel Temer (2016-2017), é inquirido por Frigotto e outros pesquisadores brasileiros, que engendram questionamentos quanto à origem das reformas educacionais que 0 ensino propedêutico e profissionalizante têm experimentado desde a Reforma Capanema, promulgada em 9 de abril de 1942, Lei Orgânica do Ensino Secundário. Essa Reforma, elitista e conservadora, materializou o dualismo educacional ao definir que o ensino secundário público seria proposto às elites dominantes e o ensino profissionalizante às classes populares. Realidade análoga ao atual contexto do ensino médio brasileiro calcado no imperativo produtivista.

Na concepção de Frigotto (2017), a Lei n. ${ }^{13.415 / 2017 ~ n a ̃ o ~ p r o m o v e ~ a ~ n e c e s s a ́ r i a ~}$ ruptura com o modelo dualista educacional brasileiro (uma escola para pobres e uma escola para os ricos), por condensar tríplice retrocesso histórico: criação de itinerários estanques não equivalentes; profissionalização precária frente ao orçamento insuficiente; e divisão classista à luz do argumento de "livre escolha" pelo ensino profissionalizante nas esferas pública e privada. Em suas palavras, a Reforma 
SANTOS, D. P.; CARVALHO, E. S. de

[...] apresenta rigidez no tocante à implementação das disciplinas recomendadas pelos organismos internacionais, intelectuais coletivos e orgânicos do capital e do mercado e na negação tácita do conhecimento básico para uma leitura autônoma da realidade social esta acobertada pela delegação da "livre escolha" do jovem dentre as opções ofertadas. [...] trata-se de uma contrarreforma que expressa e consolida o projeto da classe dominante brasileira em sua marca antinacional, antipovo, antieducação pública, que nega os fundamentos das ciências que permitem aos jovens entender e dominar como funciona o mundo das coisas e a sociedade humana (FRIGOTTO, 2017, p. 368-369).

Frigotto (2017) denuncia que essa problemática é contínua no curso da história da educação brasileira e alerta sobre os malefícios de um projeto educacional que não prima pela equidade social por desconsiderar os problemas estruturais do ensino médio brasileiro, seja a desvalorização dos professores, seja o número de alunos por classe, seja a defasagem da escola perante as novas tecnologias do mundo digital. A esse respeito, é oportuno frisar que o ensino médio contemporâneo retoma elementos estruturantes da Lei de Diretrizes e Bases n..$^{\circ}$ 5692/71, segundo a qual o ensino médio assumiu um caráter essencialmente profissionalizante devido à crença de que tal grau de ensino deveria, sobretudo, treinar os estudantes para o mundo do trabalho. No entanto, vale lembrar que essa proposição foi calamitosa e operou, na verdade, para "conter o aumento da demanda de vagas aos cursos superiores" (NASCIMENTO, 2007, p. 83) e, com isso, também dividir ainda mais a juventude, entre aqueles que ascenderiam e os que não teriam acesso ao Ensino Superior. Trata-se, pois, do risco de condenar significativa parte da juventude à condição de pura mão de obra para o mercado.

\section{A MERCANTILIZAÇÃO DA EDUCAÇÃO E O RISCO DA PRIVATIZAÇÃO}

Importa destacar que, no Brasil, a passagem do Estado capitalista desenvolvimentista para o Estado neoliberal teve seguramente um aprofundamento com o governo de Fernando Henrique Cardoso, presidente entre 1995 e 2002. Nota-se que na política educacional, com a implementação da LDB em 1996, diversas ideias vindas do mercado foram implementadas mediante 0 uso de conceitos como medição de desempenho, universalização e obrigatoriedade do ensino básico. Nesse sentido, foram enfocadas, sobretudo, políticas de formação de mão de obra para o mercado de trabalho em detrimento de uma formação integral e humanizadora, seguindo a orientação sistemática dada pelo Banco Internacional para Reconstrução e Desenvolvimento (SAVIANI, 2008).

Com efeito, entende-se que a influência do neoliberalismo na educação tem como consequência uma geração formada para o trabalho, que está em mutação continuamente, por isso o discurso focalizado em equipes, adaptável a quaisquer empresas e condições, sendo volátil como o interesse do capital. Entretanto, tem-se como perspectiva educacional o domínio da técnica desvinculado da capacidade de formular questionamentos que possam alterar a ordem social.

Nesse sentido, Freitas (2018, p. 56) analisa que 
O setor público vai sendo asfixiado enquanto a iniciativa privada se desenvolve utilizando o dinheiro público que deveria estar sendo aplicado na expansão da educação pública. A reforma empresarial da educação tem uma agenda oculta do seu discurso da "qualidade da educação para todos" que está além das formas que vai assumindo: trata-se da destruição do sistema público, por meio de sua conversão em uma organização empresarial inserida no livre mercado.

Desse modo, o sistema público vai sendo destruído gradativamente de acordo com a diminuição de verba recebida, que passa a ser destinada ao financiamento do setor privado. Mediante essa lógica, elimina-se a gestão pública do Estado sobre a Educação, possibilitando, assim, o alcance do objetivo neoliberal de se "obter pelo acesso à gestão, controle do processo educativo da juventude [...] (Ibid., p. 55)". Sobre essa intenção de controle,

\begin{abstract}
A insistência da reforma empresarial para que a escola se restrinja à "aprendizagem das disciplinas básicas" é uma demanda de longa data do status quo, assustado com a possibilidade de que os processos de trabalho inevitavelmente baseados em maior uso de tecnologia, ao demandarem mais instrução, acabem por "educar demais a mão de obra", levando-a a níveis de conscientização maiores que mobilizem e coloquem em xeque o próprio status quo" (lbid., p. 83; grifo do autor).
\end{abstract}

Destarte, o interesse neoliberal sobre a educação consiste na efetivação de uma educação hegemônica através do controle dos processos educativos, buscando impedir que os filhos dos trabalhadores possam ter a mesma educação que a camada dirigente, o que ameaçaria a organização atual, baseada na divisão social do trabalho inerente status $q u o^{3}$. Ou seja, os neoliberais lutam para construir uma escola que sirva aos seus interesses.

Segundo Freitas (2018), no pensamento neoliberal a qualidade da educação depende da inserção das escolas, professores e estudantes em um jogo concorrencial, do qual ela insurgiria, então, sem a intervenção do Estado. Nesse caso, as tentativas de terceirização e de privatização, a dinâmica de padronização por meio de base nacional comum curricular e a implementação de sistemas de avaliação centrados em testes censitários e na responsabilização meritocrática são tomadas como indutoras da inclusão da educação no mercado. Logo,

[...] se o mundo é pautado pela concorrência, há que se preparar as crianças para "competir" nele, tal como ele é. Nenhuma perspectiva de humanização ou transformação social é agregada aos processos educativos, daí seu caráter reacionário e conservador. É esta visão social que também embasa as "soluções" propostas pela engenharia da reforma empresarial na educação. Pensando a escola como uma "empresa", [...] os processos educativos têm de ser "padronizados" e submetidos a "controle". A educação, vista como um "serviço" que se adquire, e não mais como um direito, deve ser afastada do Estado, o que justifica sua privatização (FREITAS, 2018, p. 28-29). 
Essa abordagem evidencia que restringir o sentido social da educação aos ditames do lucro significa um esvaziamento tanto do conceito de educação quanto de seu sentido para a equidade e concretização das relações postas na sociedade contemporânea. Esse empobrecimento do conceito de educação faz-se também como efeito das negociações e orientações propostas pela Organização Mundial do Comércio (OMC) e pelos Tratados de Livre Comércio (TLC), cujos princípios e objetivos são estabelecidos pelas regras do livre mercado e segundo os interesses da exploração da mais-valia, isso em contraposição à educação como bem público e dever do Estado.

Nessa perspectiva, está implícita a separação entre aqueles que concebem e controlam o processo de trabalho e aqueles que irão dar-lhe cumprimento. Freitas (2018, p. 32) conjetura a possibilidade de que, num futuro próximo, os pais dos estudantes brasileiros passarão a ser "clientes" das empresas educacionais, e não mais "usuários" de um serviço público. Desse modo, a educação passa a ser vista como mercadoria a ser comprada, de forma que os pais poderão escolher no mercado qual "empresa" Ihe oferece melhor educação, e contratá-la mediante pagamento com vouchers, que seriam disponibilizados pelo Estado com a utilização de recursos públicos.

Paradoxalmente, enxerga-se a necessidade da existência de algumas poucas escolas públicas, sob a condição de atender aos sujeitos que "fracassaram na vida". Sob esse prisma, segundo Maclean (2017 apud FREITAS, 2018, p. 212), "uma pessoa que fracassa em guardar dinheiro para suas necessidades futuras deve ser tratada como um membro inferior da espécie, similar [...] aos animais que são dependentes". Assim, inferimos que, para o neoliberalismo, todas as pessoas são igualmente dotadas de condições para definir sua posição social, mediante o esforço pessoal, não sendo necessária, portanto, a ação do Estado, pois sua interferência atrapalharia a liberdade individual de competir. Nega-se, dessa forma, a necessidade da existência de serviços públicos gratuitos, excluindo, especialmente, o serviço educacional.

O mesmo autor afirma que essa concepção motiva a defesa da profissionalização no ensino médio, amplamente difundida e atualmente implementada pela Reforma do Ensino Médio (Lei n.o 13.415) a qual prioriza o dualismo histórico existente, em que a educação profissional é destinada àqueles que estão sendo preparados para executar o processo de trabalho, e a educação científico-acadêmica ofertada àqueles que vão conceber e controlar esse processo. Essa visão, que separa a educação geral, propedêutica, da educação específica e profissionalizante, é capaz de reduzir a educação profissional a treinamentos para preenchimentos de postos de trabalho. Para Freitas $(2018$, p. 84),

\begin{abstract}
Daí por que a reforma empresarial defende também a profissionalização no Ensino Médio (implementada pela atual reforma do Ensino Médio com a desculpa de que hoje ele não é "atrativo") criando uma linha de exclusão que vai do Ensino Médio para as empresas (profissionalização), uma parcela da juventude fica algum tempo dentro do sistema de Ensino Médio e sai, denunciando sua má formação através da evasão; com a profissionalização precoce, essa mesma parcela é desviada para o trabalho, saindo oficialmente das estatísticas de abandono escolar.
\end{abstract}


Na contramão dessa proposição, tem-se a educação ofertada pela Rede Federal de Educação Profissional, Científica e Tecnológica, que prevê a formação e qualificação de cidadãos para "atuação profissional nos diversos setores da economia, com ênfase no desenvolvimento socioeconômico local, regional e nacional" (BRASIL, 2008). Essa Rede tem como compromisso a formação de sujeitos críticos, humanizados e emancipados, através de uma educação que proporcione experiências com o intuito de despertar o

[...] senso crítico, elevando o sujeito a patamares de compreensão capazes de ampliar seu nível de participação na esfera social, sem negligenciar a relação do homem com as questões de socialização, com as tecnologias, com os desafios ambientais e com a totalidade do complexo mundo do trabalho (FDE/CONIF, 2016, p. 12).

Isso implica considerar que os Institutos Federais almejam o desenvolvimento de um projeto educacional centrado na qualificação, nos processos educativos democráticos capazes de favorecer inclusão social emancipatória, contribuindo para a efetivação de uma sociedade igualitária. Desse modo, comparecem como resistência à ameaça neoliberal, que assola essa concepção de educação, lutando por uma educação verdadeiramente de qualidade.

\section{A FORMAÇÃO OMNILATERAL NO ENSINO MÉDIO INTEGRADO NA REDE FEDERAL DE EDUCAÇÃO PROFISSIONAL E TECNOLÓGICA}

Conforme a Lei no 11.892/2008, os Institutos Federais de Educação, Ciência e Tecnologia ofertam desde educação técnica integrada ao ensino médio até a pósgraduação. Eles buscam atuar de modo integrado, alicerçando suas ações no tripé trabalho, cultura e ciência, como forma de assegurar a emancipação humana. Nessa perspectiva, a formação profissional é concebida como espaço para o aprofundamento de saberes e, simultaneamente, para a refutação de tônicas sociais excludentes. Nas palavras de Ramos (2007, p. 3), "uma educação dessa natureza precisa ser politécnica, isto é, uma educação que, ao propiciar aos sujeitos o acesso aos conhecimentos e à cultura construídos pela humanidade, propicie a realização de escolhas e a construção de caminhos para a produção da vida".

Nesse sentido, o ensino médio integrado tem como objetivo promover, de um lado, a superação da dualidade escolar entre formação geral e profissional, de outro, o incentivo à formação "integral", embasada numa noção de "politecnia", respaldada na formação do homem omnilateral ${ }^{4}$. A noção de politecnia ou instrução politécnica é parte da formação integral. No que tange à educação do corpo, esta deveria equilibrar os efeitos nocivos do trabalho à saúde, sobretudo no sistema industrial. Em relação à dimensão intelectual, considera-se a necessidade de abranger a totalidade das ciências, pois, com o domínio dos conhecimentos científicos e tecnológicos que explicam e fundamentam o trabalho produtivo, a classe operária poderia romper as desigualdades sociais. Nesse caso, a formação omnilateral faz-se em oposição à formação unilateral causada pelo trabalho alienado, pela divisão social do trabalho, pela reificação, pelas relações burguesas. 
SANTOS, D. P.; CARVALHO, E. S. de

Para Ramos (2007, p. 3-4), o primeiro sentido dessa integração é filosófico, visto que se manifesta na

[...] concepção de formação humana, com base na integração de todas as dimensões da vida no processo formativo. $O$ primeiro sentido da integração ainda não considera a forma ou se a formação é geral ou profissionalizante. O primeiro sentido da integração pode orientar tanto a educação básica quanto a educação superior. A integração, no primeiro sentido, possibilita formação omnilateral dos sujeitos, pois implica a integração das dimensões fundamentais da vida que estruturam a prática social. Essas dimensões são o trabalho, a ciência e a cultura. $O$ trabalho compreendido como realização humana inerente ao ser (sentido ontológico) e como prática econômica (sentido histórico associado ao respectivo modo de produção); a ciência compreendida como os conhecimentos produzidos pela humanidade que possibilita o contraditório avanço produtivo; e a cultura, que corresponde aos Ravalores éticos e estéticos que orientam as normas de conduta de uma sociedade.

Nesse caso, o trabalho é tomado em seu sentido ontológico, ou seja, intrínseco à vida humana, e não meramente pela comercialização de força produtiva para ganho financeiro. Portanto, "trabalho é produção, criação, realização humanas. Compreender o trabalho nessa perspectiva é compreender a história da humanidade, as suas lutas e conquistas mediadas pelo conhecimento humano (RAMOS, 2007, p. 4)". Portanto, considera-se a formação profissional como espaço para o aprofundamento de saberes e, simultaneamente, para a refutação de tônicas sociais excludentes. Assim ela está pautada, sobretudo, pelos referenciais gramscianos, ${ }^{5}$ considerando-se uma escola unitária, tendo o trabalho como princípio educativo, de modo que o sujeito seja formado para ser produtor de sua história, apropriando-se dela e podendo transformá-la. Busca-se assim uma escola que seja capaz de promover a formação "integral", embasada numa noção de "politecnia", fundamentada na formação do homem omnilateral.

À luz desse entendimento, foi elaborada, em novembro de 2017, uma minuta de Parâmetros Gerais, que busca promover elementos que fundamentem a resistência em prol dos Cursos Integrados na Rede de EPCT. Essa minuta foi criada durante reunião do Fórum de Dirigentes de Ensino-FDE, formado pelo Grupo de Trabalho dos Cursos Integrados, na qual foi proposta ao Conselho Nacional das Instituições da Rede Federal de Educação Profissional, Científica e Tecnológica-Conif a organização de diretrizes ou parâmetros gerais para a oferta de cursos integrados como política prioritária de educação profissional na Rede Federal de Educação Profissional, Científica e TecnológicaRede Federal de EPCT. Para isso, também foram elaborados dois documentos, um em 2016, o Documento Base para a promoção da formação integral, fortalecimento do ensino médio integrado e implementação do currículo integrado no âmbito das Instituições da Rede EPCT, conforme Lei no 11.892/2008; e outro em 2017, a Agenda de Fortalecimento do Ensino Médio Integrado na Rede Federal.

Na minuta, são abordadas considerações acerca dos 
Dados dos cursos integrados na Plataforma Nilo Peçanha - PNP; Fundamentos e base legal dos Cursos Integrados; Reflexão sobre os cursos integrados no FDE - documentos de 2016 e 2017; Parâmetros gerais para os Cursos Integrados na Rede Federal de EPCT (FDE/CONIF, 2016, p. 2).

Nesse documento foi evidenciada a necessidade de criação de vagas para cursos técnicos, priorizando os cursos integrados e almejando, dessa forma, o cumprimento do que está determinado no art. $8^{\circ}$ da Lei n 11.892/2008: "No desenvolvimento da sua ação acadêmica, o Instituto Federal, em cada exercício, deverá garantir o mínimo de 50\% (cinquenta por cento) de suas vagas para atender aos objetivos definidos no inciso I do caput do art. 7" (BRASIL, 2008). De acordo com a Plataforma Nilo Peçanha -PNP6, para se garantir essa determinação legal, será preciso ampliar em torno de $8 \%$ do total de suas vagas, o que seria aproximadamente 40 mil vagas a mais para a oferta de Cursos Integrados.

Outro dado importante que a PNP apresenta refere-se ao público atendido pelos Cursos Integrados da Rede Federal de EPCT, validando, por meio dos resultados de pesquisa socioeconômica, que a rede está alcançando o público que mais carece de formação integrada:

[...] quadro socioeconômico do país ainda evidencia a necessidade da educação como estratégia de desenvolvimento e inclusão social para a garantia do acesso, permanência e êxito de estudantes em sua trajetória acadêmica. [...]. Quando o quesito é Renda Familiar, embora $45 \%$ não tenha declarado renda, a maioria dos que declararam situam-se na faixa de renda de até 1,5 Salários Mínimos per capita, [...]. Excluindo-se o percentual de Não Definidos - N/D, que do ponto de vista estatístico deveriam ser distribuídos proporcionalmente nos estratos, 74\% dos estudantes são oriundos de famílias de até 1,5 SM per capita (FDE/CONIF, 2016, p. 7).

Quanto aos fundamentos e base legal dos Cursos Integrados, a minuta evidencia a Lei no 11.892/2008, que dispõe sobre a criação dos IF, reiterando que a oferta de Cursos Integrados é uma determinação legal para a Rede Federal de EPCT, não cabendo, portanto, a alternativa de não ofertamento. Cita também o Parecer CNE/CEB no 11/2012, que deu origem à Resolução CNE/CEB no 06/2012, que estabelece que Educação Profissional

É uma importante estratégia para o efetivo acesso às conquistas científicas e tecnológicas da sociedade. Impõe a superação do enfoque tradicional da formação profissional baseado apenas na preparação para execução de um determinado conjunto de tarefas. Requer, além do domínio operacional de um determinado fazer, a compreensão global do processo produtivo, com a apreensão do saber tecnológico, a valorização da cultura do trabalho e a mobilização dos valores necessários à tomada de decisões no mundo do trabalho. Deve estar centrada no compromisso de oferta de uma Educação ampla e politécnica (FDE/CONIF, 2016, p. 9). 
SANTOS, D. P.; CARVALHO, E. S. de

Essa proposição reitera que a educação ofertada pela Rede Federal visa ao acesso ao conhecimento científico e tecnológico acumulado pela sociedade, afastando-se de uma educação destinada apenas para formação de mão de obra, fundamentando-se, para isso, na concepção de formação omnilateral. Logo, pretende ofertar um modelo de educação que assegure a democracia, os direitos constitucionais, contribuindo para a efetivação de uma sociedade igualitária.

A minuta aborda uma análise de como as alterações na LDB podem influenciar a oferta dos Cursos Integrados da Rede Federal, primeiramente ressaltando que a oferta dos Cursos Integrados é uma determinação legal respaldada na Resolução CNE/CEB n. ${ }^{\circ}$ 06/2012. Desse modo, é evidenciado que a oferta dos Cursos Integrados não se confronta com a Lei no 13.415/2017, que alterou a LDB, conforme exposto:

É importante ressaltar, por fim, que a Lei n. ${ }^{\circ}$ 13.415/2017 alterou a LDB no que diz respeito ao Ensino Médio, como última etapa da Educação Básica, e não no capítulo que diz respeito à Educação Profissional. A continuidade da oferta dos Cursos Integrados na Rede Federal de EPCT continua sendo uma determinação legal, na lei educacional vigente e não está em contradição, do ponto de vista legal, com as alterações na LDB (FDE/CONIF, 2016, p. 13).

Sobre a qualidade da educação profissional dos cursos técnicos integrados, foi posto no documento que essa não pode se limitar a rendimentos de exames padronizados. De acordo com Freitas (2018), ao se colocar os testes padronizados como foco da escola, transformando suas ações com base nessas referências de qualidade, ocorre, dessa maneira, a ocultação do debate sobre as reais finalidades educativas, favorecendo a captura da ação pedagógica pelo status quo. Desse modo, de acordo com a minuta,

[...] o conceito de qualidade educacional do Ensino Médio Integrado da Rede Federal não deve se pautar apenas no uso dos resultados de exames direcionados aos estudantes (ENEM e outros exames), porque essa perspectiva não consegue responder à complexidade de todo processo educativo no contexto do Ensino Médio Integrado ofertado pela Rede Federal. Por outro lado, preparar estudantes para exames não é o objetivo e nem resume o trabalho desenvolvido pelos IFs (FDE/CONIF, 2016, p. 14).

Portanto, após a análise da minuta dos Parâmetros Gerais do Currículo Integrado de EPCT, é possível depreender que se trata de um importante documento que vislumbra princípios e objetivos da Rede Federal no que tange à discussão sobre a organização curricular e as práticas educativas. Em síntese, o conteúdo do documento apresenta elementos teóricos e legais que justificam a defesa de um modelo educacional centrado na ideia de trabalho e na pesquisa como princípio educativo que perpassa também o entendimento da curricularização da extensão ${ }^{7}$ como possibilidade de concretização da indissociabilidade ensino, pesquisa e extensão também na educação básica. Logo, mostra-se resistente à lógica posta pelos neoliberais no campo educacional. 
A esse respeito, importa salientar que o currículo integrado constitui-se um desafio que perpassa as discussões no campo educacional, instigando os profissionais da educação a buscar formas de efetivá-lo por meio de práticas que impliquem interdisciplinaridade, transversalidade, contextualização, temas geradores etc. Isso com a finalidade de garantir maior integração dos saberes escolares com os saberes cotidianos dos estudantes, de modo a combater a visão hierárquica e dogmática do conhecimento. Ora, a compreensão de formação integrada exige a superação de concepções e práticas fragmentadoras do conhecimento humano que desconsiderem sua totalidade humana. Sendo assim, o desafio é resistir ao pensamento neoliberal alicerçado em uma racionalidade economicista e neotecnicista que visa à privatização da educação pública, buscando, inclusive, identificar modos de se fazer a mediação entre diferentes saberes. É sabido, pois, não haver alternativas prontas ou propostas simplificadas quando se trata de educação, sobretudo quando se almeja o desenvolvimento de uma perspectiva integral de desenvolvimento humano.

Logo, é imperativa a defesa da formação verdadeiramente integral do ser humano, pressupondo estabelecer, nos currículos e na prática político-pedagógica das instituições de ensino, a articulação entre educação, cultura, arte, ciência e tecnologia, nos enunciados teóricos, metodológicos, políticos e pedagógicos da ação educativa institucional. Trata-se, portanto, de pensar a educação para além da instrumentalização de mão de obra para o mercado. As críticas ao neoliberalismo pautam-se especialmente no foco da implantação, pela via dos organismos internacionais, de uma agenda única de desenvolvimento que nega as singularidades de cada nação.

\section{CONSIDERAÇÕES FINAIS}

Conforme Nosella (1995), "escola do dizer" e "escola do fazer" são divisões estruturais do sistema educativo no modo capitalista de produção, ou seja, prevalecem uma escola de formação das elites e outra escola de formação do proletariado. Nessa perspectiva, está implícita a separação entre aqueles que concebem e controlam o processo de trabalho e aqueles que irão cumpri-lo; a educação profissional destinada àqueles que estão sendo preparados para executar o processo de trabalho e a educação científico-acadêmica ofertada àqueles que vão conceber e controlar esse processo. Essa visão que separa a educação geral, propedêutica, da educação específica e profissionalizante é capaz de reduzir a educação profissional a treinamentos para preenchimento de postos de trabalho.

Sob esse prisma, objetivando o enfrentamento dos desafios postos por essa realidade, considera-se essencial que a escola se constitua em um espaço privilegiado de troca de saberes, onde os trabalhadores possam ser vistos como sujeitos pensantes e ativos e não apenas potenciais empregados. Concordamos com Mészáros quanto ao verdadeiro sentido da educação, que não é negócio, e sim criação. Portanto, a educação vigente nas escolas deveria formar para a vida e não para o mercado de trabalho, e seu papel como propulsor de conhecimento incide em afastar o sujeito do individualismo produzido pelo capital, que delineia as relações de competição orientadas atualmente pelo sistema capitalista. Trata-se da tentativa de se ultrapassar a lógica desumanizadora 
do capital, que tem como bases de sustentação o individualismo, o lucro e a competição, para arquitetar a sociedade, tendo como ponto nuclear o ser humano.

Cabe, pois, buscar e "reivindicar uma educação plena para toda a vida, para que seja possível colocar em perspectiva a sua parte formal, a fim de instituir, também aí, uma reforma radical" (MÉSZÁROS, 2005, p. 55). Ora, o objetivo primordial da educação é o de elaborar, desenvolver e realizar as transformações políticas, econômicas, culturais e sociais necessárias; uma educação empenhada na construção de um outro mundo possível, que prime pelo ser humano e não apenas pela sua atividade de trabalho.

Com efeito, a educação integrada fundamenta-se em princípios científicos e tecnológicos que se instituem num espaço de síntese entre a prática e a teoria, entre o trabalho manual e o intelectual. Busca-se um projeto que vá além da educação profissional baseada no conhecimento e na aquisição de técnicas e das particularidades do mundo do trabalho, compreendendo a reflexão sobre as vivências, as experiências e o saber histórico e social do sujeito. Concebe-se, assim, uma educação humanista, na qual o humano não deve existir somente para o mundo produtivo do trabalho.

Artigo recebido em: 18/11/2019

Aprovado para publicação em: 11/03/2020

THE IMPACT OF NEOLIBERAL THOUGHT ON THE "NEW" HIGH SCHOOL REFORM- LAW №. 13.415 / 2017: PUBLIC EDUCATION AT RISK

ABSTRACT: This article discusses the issue of high school reform under the influence of neoliberal thinking in education, highlighting its dilemmas and impasses. Thus, the objective is to analyze the relationship between neoliberalism and public policies in the area of education after the promulgation of the "new" reform of high school through Law No. 13.415, sanctioned on February 16, 2017. Considering this context, the reflections presented seek to problematize the hierarchization and curricular flexibility, the emphasis on the teaching of competences and their marketing character. In contrast, the social role of the Federal Institutes of Education in favor of the defense of a high school that provides an integrated, polytechnic formation and that takes the work as an educational principle is emphasized.

KEYWORDS: Neoliberalism. High school reform. Integrated Training.

EL IMPACTO DEL PENSAMIENTO NEOLIBERAL EN LA "NUEVA" REFORMA DE LA ESCUELA SECUNDARIA - LEY N¹3.415 / 2017: LA EDUCACIÓN PÚBLICA EN RIESGO

RESUMEN: Este artículo aborda el tema de la reforma de la escuela secundaria bajo la influencia del pensamiento neoliberal en la educación, destacando sus dilemas e impases. Por lo tanto, el objetivo es analizar la relación entre el neoliberalismo y las políticas públicas en el área de la educación después de la promulgación de la "nueva" reforma de la escuela secundaria a través de la Ley $\mathrm{N}^{\circ}$ 13.415, sancionada el 16 de febrero de 2017. Considerando este contexto, las reflexiones presentadas buscan problematizar la jerarquización y la flexibilidad curricular, el énfasis en la enseñanza de competencias y su carácter de marketing. En contraste, se enfatiza el papel social de 
los Institutos Federales de Educación a favor de la defensa de una escuela secundaria que proporcione una formación politécnica integrada y que tome el trabajo como un principio educativo.

PALABRAS CLAVE: Neoliberalismo. Reforma de la escuela secundaria. Entrenamiento Integrado.

\section{NOTAS}

1) Escrevemos "Nova" Reforma entre aspas, pois entendemos que se trata da permanência de um sistema excludente, gestado no dualismo entre o ensino profissionalizante e o intelectual, cujo objetivo é perpetuar a segregação social via acesso ao conhecimento.

2) Segundo Frigotto e Ciavatta (2003), nos anos de 1990 registrou-se a forte influência dos organismos internacionais que passaram a interferir em questões organizacionais e pedagógicas, isso por meio de eventos, assessorias técnicas e abundante produção documental. Essa articulação pretendia criar e legitimar um consenso em torno da ideia de onipresença e onipotência do mercado.

3) A expressão latina status quo significa intenção de se manter o atual, seja cenário, situação ou condição etc.

4) Segundo Frigotto (2012, p. 267), o termo omnilateral "vem do latim e sua tradução literal significa "todos os lados ou dimensões".

5) Na concepção de Moura, Lima Filho e Silva (2015), Gramsci considera a educação como processo por meio do qual o homem adquire propriamente condições de humanização. Isso porque esse processo é circunstanciado pela história e pelos modos de produção da existência. Nesse processo, a integração entre trabalho, ciência e cultura comporia "o princípio educativo da escola unitária, alternativa à escola tradicional, uma escola 'desinteressada', essencialmente humanista" (Ibid., p.7). 6) A Plataforma Nilo Peçanha (PNP) consiste em uma importante fonte de acesso à pesquisa, disponibilizando à sociedade, em ambiente virtual, informações acerca de coleta, validação e disseminação das estatísticas oficiais da Rede Federal de Educação Profissional, Científica e Tecnológica.

7) A Resolução n 7, de 18 de dezembro de 2018, institui as Diretrizes para a Extensão na Educação Superior entre outras providências. Estabelece, em seu art. $3^{\circ}$, que a extensão na educação superior brasileira consiste numa atividade que deve estar integrada à matriz curricular e à pesquisa, ocorrendo, assim, de modo interdisciplinar, político, educacional, cultural, científico, tecnológico, na procura de viabilizar a interação entre as instituições de ensino superior e os outros âmbitos da sociedade por meio da produção e da aplicação dos saberes, em conexão permanente com o ensino e a pesquisa (BRASIL, 2018).

\section{REFERÊNCIAS}

BRASIL. Lei n 13.145, de 16 de fevereiro de 2017. Altera a Lei no 9.394, de 20 de dezembro de 1996, que estabelece as diretrizes e bases da educação nacional. Brasília: DOU, 2017. 
SANTOS, D. P.; CARVALHO, E. S. de

CIAVATTA, Maria. Trabalho como princípio educativo. In: CALDART, R.; PEREIRA, I.; ALENTEJANO, P.; FRIGOTTO, G. (Orgs.). Dicionário da Educação do Campo. Rio de Janeiro: Escola Politécnica de Saúde Joaquim Venâncio; São Paulo: Expressão Popular, 2012. Disponível em: http://w3.ufsm.br/gpet/index.php?option= com_content\&view=article\&id=146:pdf-catid=33:leiturasugeridas\&ltemid=48. Acesso em: 29 jan. 2019.

CIAVATTA, Maria. Formação integrada: caminhos para a construção de uma escola para os que vivem do trabalho. In: PARANÁ. O Ensino Médio integrado à educação profissional: concepções e construções a partir da implantação na Rede Pública Estadual do Paraná. Curitiba: SEED-PR, 2008. p. 6-15.

GENTILI, P. Neoliberalismo e educação: manual do usuário. In: SILVA, T. T. da \&

GENTILI, P. (Orgs.). Escola S.A.: quem ganha e quem perde no mercado educacional do neoliberalismo. Brasília, DF: CNTE, 1996, p. 9-49.

FDE/CONIF. Documento Base para a promoção da formação integral, fortalecimento do ensino médio integrado e implementação do currículo integrado no âmbito das Instituições da Rede EPCT conforme Lei 11.892/2008. Brasília, 11 maio 2016. Disponível em: http://portal1.iff.edu.br/nossos-campi/camposcentro/diretoria-de-educacao-basica-e-profissional/arquivos-da-diretoria-de-ensinobasico-e-profissional/documento-base-ensino-medio-integrado-na-rede-epct-fde-maio2016.pdf. Acesso em: 5 ago. 2019.

FREITAS, L. C. A reforma empresarial da educação: nova direita, velhas ideias. São Paulo: Expressão Popular, 2018.

FRIGOTTO, G.; CIAVATTA, M.; RAMOS, M. (Org.) Ensino Médio Integrado: concepção e contradições. São Paulo: Cortez, 2005.

FRIGOTTO, G; CIAVATTA, Maria (2003). Educação básica no Brasil na década de 1990: subordinação ativa e consentida à lógica do mercado. Revista Educ. Soc., Campinas, v. 24, n. 82. Acesso em: 23 outubro. 2019. Disponível em:

http://www.scielo.br/scielo.php?=S0101-73302003000100005\&lng=pt\&nrm=iso

FRIGOTTO, Gaudêncio. A gênese das teses do Escola sem Partido: esfinge e ovo de serpente que ameaçam a sociedade e a educação. In: FRIGOTTO, Gaudêncio (Org.).

Escola "sem" Partido: esfinge que ameaça a educação e a sociedade brasileira. Rio de Janeiro: UERJ, LPP, 2017. p. 361-369.

IANNI, Octavio. A Sociologia e o mundo moderno. Tempo Social, Rev. Sociol. USP, S. Paulo, v. 1, n. 1, p. 7-27, 1 sem. 1989. 
MÉSZÁROS, István. A educação para além do capital. 2. ed. São Paulo: Boitempo, 2008.

MOTTA, Vânia Cardoso; FRIGOTTO, Gaudêncio. Por que a urgência da Reforma do Ensino Médio? Medida Provisória nº 746/2016 (Lei no 13.415/2017). Educação \& Sociedade, Campinas, 2017, v. 38, n. 139, p. 355-372, 2017.

NASCIMENTO, Manoel Nelito M. Ensino Médio no Brasil: determinações históricas.

\section{Publicatio UEPG: Ciências Humanas, Ciências Sociais}

Aplicadas, Linguística, Letras e Artes, Ponta Grossa, v. 15, n. 1, jun. 2007. Disponível em: www.revistas2.uepg.br/index.php/sociais/article/download/2812/2097. Acesso em: 22 jan. 2017.

NOSELLA, P. Prefácio. In: MANACORDA, M. (Org.). História da Educação: da antiguidade aos nossos dias. 4. ed. São Paulo: Cortez, 1995.

RAMOS, Marise N. Possibilidades e Desafios na Organização do Currículo Integrado. In: In: RAMOS, Marise N. (Org.); FRIGOTTO, Gaudêncio (Org.); CIAVATTA, Maria (Org.) Ensino Médio Integrado: Concepção e Contradições. 1. ed. São Paulo: Cortez, 2007.

SAVIANI, D. Pedagogia histórico-crítica: primeiras aproximações. São Paulo: Autores Associados, 2011.

Dayanna PereiRa Santos: Pedagoga, mestre e doutora em Educação pela Universidade Federal de Goiás. Atualmente é professora no Instituto Federal de Educação, Ciência e Tecnologia de Goiás e exerce atividades de ensino, pesquisa e extensão. Atua como membro do Colegiado Docente do Programa de Pós-Graduação - Mestrado Profissional em Rede em Educação Profissional e Tecnológica (ProfEPT) do IFG.

Orcid: https://orcid.org/0000-0002-8484-3966

E-mail: dayannasyn@hotmail.com

EdSOn SILVA de CARVALHO: Mestre em Educação Profissional e Tecnológica pelo Instituto Federal de Educação, Ciência e Tecnologia do Espírito Santo. Possui graduação em Matemática (2013) e graduação em Administração pela Universidade Paulista. Atualmente é Técnico em Assuntos Educacionais do Instituto Federal de Educação, Ciência e Tecnologia de Goiás. 
SANTOS, D. P.; CARVALHO, E. S. de

Orcid: https://orcid.org/ 0000-0002-9831-0415

E-mail: edson.carvalho@ifg.edu.br

Este periódico utiliza a licença Creative Commons Attribution 3.0, para periódicos de acesso aberto (Open Archives Iniciative - OAI). 